\title{
The Role of Human Resource Management in Employee Motivation and Performance-An Overview
}

\author{
Hassan Elsan Mansaray \\ Lecturer-Department of Business Administration and Entrepreneurship Development, Institute of Public \\ Administration and Management (IPAM) University of Sierra Leone, Freetown, Sierra Leone \\ hassanelsan@gmail.com
}

\begin{abstract}
This paper discusses the link between motivation and performance, and established what makes motivation to have a central role in getting high performances from employees in organizations. It was revealed from the review that there are several motivational theories used by employers at different situations when they want their employees to highly perform. As motivation is to influence employees to perform, hence; performance is the evaluation with respect to acknowledged tasks, objectives, goal line and rational anticipations linked with a role, occupation in an organization. This paper has looked at some of these theories that have been proven and accepted by the general public. They comprise Maslow's hierarchy of needs, McGregor's theories $x$ and $y$, McClelland's theory of learned needs, Alderfer's ERG theory, Herzberg's two-factor theory, Vroom's expectancy theory and different types of motivation, such as intrinsic and extrinsic. It is evident from the literature reviewed that all theories were established on some experimentations or observations, as a result they are just written ends about a tested situation. Though circumstances can be comparable, they will perhaps by no means be the same. Also, studies have showed that highly motivated employees that are productive and innovative can lead the organization to success through the achievement of its desired results.
\end{abstract}

Keywords : human resource managemen; motivation; performance; work/job performance; performance management; performance appraisal; organization; reward; commitment

\section{Introduction}

In the commencement of 1960, John Kenneth Galbraith was demonstrating the importance of human resources paralleled to the technical resources: "Should machines represent the decisive aspect, the social arrangements that help us develop our infrastructure and the equipment are those of prime importance. But if people are the ones that matter, our first concern should be creating those arrangements that help conserve and develop personal talents" (Ni!ă 2010 cited in Elena N. I n.d:1039). It is based on Galbraith phenomenon that makes motivation to have a pivotal role in getting 'high performances' from employees in organizations. However, in order to achieve 'high performance' in firms; managers should have the capability to produce a helpful organizational environment that could enable employees to work (Rusua and Avasilcaia 2014). As motivating people is about making them to change to the course you want them to go so as to get result. Nevertheless, employees can only display 'high performance' if they are soundly inspired and eager to workout optional effort (Armstrong 2009).

Moreover, study had shown that a business continuing achievement center on to a great degree on taking exceptionally 'motivated employees' who are industrious and resourceful. Therefore, it is essential to comprehend the connection 'between motivation and performance' and; establish whatever will motivate your employees. It is likewise important to know how you manage 'employees' performance and how you reward them, 'not just in terms of salary but, for example, through recognition and other incentives'. Highly-motivated employees are probably to go that further mile to satisfy you. On the other hand, affecting appropriate 
inducements isn't quite adequate; the employer also have a duty to monitor the usefulness of the enticements. (Better Workplaces n.d:67).

Thus, motivation is therefore, defined by various authors like McShane \& Von Glinow (2000:66) and Robins and Coulter (2012) as referring 'to the powers/efforts inside a person that moves his or her direction, intensity, and persistence of voluntary behavior'. [In this case] inspired employees are enthusiastic to apply a precise level of strength (intensity/ energy) for a definite quantity of period (persistence), toward a specific goal (direction). In addition, Bateman and Snell (2013) in the same way referred to motivation as forces that energize, direct, and sustain a person's effort. They said, all behaviors, expect voluntary reflexes like eye blinks (which have little to do with management), and are motivated. They further stated that a highly motivated person will work hard toward attaining performance goals. Through satisfactory skill and understanding of the job, as well as the right to use the necessary resources, which will make the person to be highly productive. They additionally pointed out that to be real motivators, is obligatory to managers to know what behavior employees need to display to earn motivation. Even though productive people seem to do apparently boundless number of things, therefore, most of the important activities can be grouped into five general categories on how Managers must motivate people. Such as to (1) join the organization, (2) remain in the organization, and (3) come to work regularly. On these points, you should reject the common recent notion that loyalty is dead and accept the challenge of creating an environment that will attract and energize people so that they commit to (4) performance- that is, once employees are at work, they should work hard to achieve high output and high quality. Lastly, managers want employees to (5) exhibit good citizenship. Good citizens of the organization are committed, satisfied employees who perform above doing extra things that can help the company.

As motivation is to influence employees to perform, hence; performance is the evaluation with respect to acknowledged tasks, objectives, goal line and rational anticipations linked with a role, occupation in an industry/organization. Any action or process that can be associated to performing a task or function can be classified as performance. As a result, work performance is just how fine an individual completes a job, role, task or responsibility. This includes concrete things such as revenue targets and imperceptible things such as communication (Spacey J. 2017). Besides, Performance management can be defined as a practice by which organizations established goals, regulate standards, ascribe and appraise work, and mete out rewards. In consequence, it is used to develop organizational team and individual performance and development, as well as events envisioned to guarantee that goals are unfailingly being met in an operative and proficient manner, (McMahon G 2013).

\section{Literature Review}

\subsection{Motivational Theories}

Several diverse theories have existed that attempted and supported to explain the concept of motivation. More so, researchers have been learning the theme of motivation for many years and have made marvelous advancement for expounding motivation that can be construed in the workplace. This paper is going to look at some of these theories that have been proven and accepted by the general public. They comprise Maslow's hierarchy of needs, McGregor's theories $x$ and $y$, McClelland's theory of learned needs, Alderfer's ERG theory, Herzberg's two-factor theory, Vroom's expectancy theory and different types of motivation, such as intrinsic and extrinsic. More so, many scientific researchers have learned that motivational 
theories vary amongst themselves according to how they describe behavior over motivation content or through strong-minded psychological processes. Most of these theories can be separated into three basic types: content/needs theories, process/cognitive theories and strengthening/reinforcement theories. Even though additional legal clarifications have been advanced, these initial theories are essential as they embody the basis from which current motivation theories were established and since several practicing managers still use these theories (Burton K, 2012, Robins \& Coulter 2012, Armstrong, 2009, Luthans \& Doh, 2009 and Elena, n.d).

\subsection{Maslow's Hierarchy of Needs Theory}

One of the first and best-known content theories to describe why people have dissimilar needs at diverse times is Abraham Maslow's needs hierarchy theory discovered in the late 1943 and formulated in 1954. He revealed five basic classes of human needs and positioned them in a hierarchy (Burtin K, 2012, Robins \& Coulter 2012, Armstrong 2009, Luthans \& Doh 2009 and McShane 2000). Maslow hypothesized that everybody has five basic needs that create a need hierarchy. In ascending order, starting with the simplest needs such as:

Physiological needs - like water, food, sex, clothing, and shelter. Maslow opposed that an individual's determination to fulfill these biological needs is bigger than the ambition to satisfy any other type of need. In the context of work motivation, these physiological needs often are satisfied through the wages and salaries paid by the organization.

Safety needs - are wishes for security (i.e. protection from physical and emotional harm), as well as assurance that physical needs will be met (stability), and absence of pain. Organizations usually support personnel to satisfy these needs through safety programs and equipment and by providing security through medical insurance, unemployment and retirement plans, and related benefits.

Social needs - a person's need for affection, belongingness, acceptance, and friendship. This want for "belongingness" frequently is contented on the job over social collaboration within work groups in which people give and receive friendship. Social needs can be satisfied not only in officially dispensed work groups but also informal groups

Esteem needs - are desires for power and status. Individual need to feel vital and get recognition from others. More importantly, receives promotions, awards, and feedback from the boss that will lead to self-confidence, prestige, and self-important; and

Self-actualization needs - which represents the need for self-fulfillment - a sense that the person's potential has been achieved. In an organization, an individual may attain selfactualization not over promotion but in its place by mastering his or her environment and setting and achieving goals (Robins \& Coulter 2012, Luthans \& Doh 2009 and McShane 2000). However, Maslow's 1954 model does not take account of "money", which suggest that he does not consider the need for money is essential. In practice all the same, "money plays a part at every level of the model, which helps us recognize how monetary reward functions as a means to an end, rather than an end in itself' (Mead \& Andrews 2009).

\subsection{Mcgregor's Theories $\mathrm{X}$ and $\mathrm{Y}$}

Douglas McGregor (1960) shaped his study in diverse interpretations about people and in what way they should be motivated. He improved two opposite models of managerial method identified as Theory X and Theory Y. McGregor found out two stunningly dissimilar sets of expectations thought by managers about their employees. Which Stráníková (2008) 
described as 'two possible views on human beings'. Theory $\mathrm{X}$ is the old-fashioned view of managers who only focused on the individual work and are 'job centred'. They presumed that the ordinary human being or workers have minute determination, distastes work and desires to circumvent responsibility and therefore cannot be trusted. And they need to be closely controlled, coerced, directed, and threatened with punishment to get them to work effectively. Theory $\mathrm{X}$ was criticized for the reason that it denies employees of the chances to placate what Maslow recognized as higher-level social needs of self-esteem and self-actualisation.

In contrast, theory Y stresses that people will exercise self-direction in the service of the objectives that they are committed to. Theory Y perceives employees in more satisfactory light. The theory 'is more employee-centred style of management capable of fully exploiting the creative and productive potential of employees'. Theory Y was made on the supposition that 'mental and physical efforts in work' is as usual as 'play and rest'; that an ordinary person does not disinclined work but would see it as a basis of 'reward or punishment' that is contingent upon well-regulated situations. Therefore, commitment to objectives should be linked to the rewards associated with their achievement. Thus, Robins and Coulter (2012) and Stráníková (2008) pointed out that 'theory $\mathrm{Y}$ is a positive view that assumes employees enjoy work, seek out and accept responsibility, and exercise self-direction. McGregor believed that Theory Y assumptions should guide management practice and proposed that participation in decision making, responsible and challenging jobs, and good group relations would maximize employee motivation.

\subsection{Alderfer's Erg Theory}

ERG was established by Clayton Alderfer to overawe the difficulties with Maslow needs hierarchy. 'ERG theory groups human needs into three broad categories: existence, relatedness, and growth. However, the theory's name is created on the first letter of each need: $E=$ existence, $\mathrm{R}=$ relatedness, and $\mathrm{G}=$ growth.

Existence needs take account of a person's psychological and physically related safety needs, such as the need for food, shelter, and safe working conditions.

Relatedness needs consist of a person's need to interact with other people, get public recognition, and feel safe and sound around people (i.e., interpersonal safety).

Growth needs include a person's self-esteem through personal achievement as well as the concept of self-actualization (Bateman \& Snell 2013, Robins \& Coulter, 2012 and McShane \&Von Glinow 2000).

Unlike Maslow's model, nonetheless, ERG theory consist of 'a frustration regression process' whereby those who are not capable to satisfy a higher need turn out to be frustrated and retrogress to the next lower need level. For example, if existence and relatedness needs have been contented but growth need achievement has been blocked, the individual will become discouraged and relatedness needs will again emerge as the central source of motivation (McShane \&Von Glinow 2000).

\subsection{McClelland's Theory of Learned Needs}

McClelland D. (1973) dedicated his vocation 'to studying three secondary needs that he considered particularly important sources of motivation:

Need for achievement - People with a high need for achievement (nAch) want to achieve rational thought-provoking goals over their own hard work. Hence, they have a preference of 
'working alone rather than in teams because of their strong need to assume personal responsibility for tasks'. High nAch people are as a result best at ease 'when their jobs offer challenge, feedback, and recognition'.

Need for affiliation - need for affiliation (nAff) talks about the desire to search for authorization from others, 'conform to their desires and hopes, and 'avoid conflict and confrontation' with them. Those people with a sturdy nAff 'want to form positive relationships with others'. They try to plan a promising appearance lof themselves and take other steps to be liked by others $\backslash$. Moreover, 'high nAff employees actively support others and try to smooth out conflicts that occur in meetings and other social settings'.

And; the Need for power - need for power (nPow) denotes the desire to regulate 'one's environment, including people and material resources'. People with high nPow always 'want to exercise control over others and are worried about upholding their leadership position. They often depend on convincing communication, necessitate 'more suggestions in meetings, and tend to publicly evaluate situations more frequently'.

On the other hand, McClelland (1973) developed an alternative approach in 'classifying needs' based largely on observing managers. In his observation, 'he identified three needs as being most important:

- The need for achievement, defined as the need for competitive success measured against a personal standard of excellence.

- The need for affiliation, defined as the need for warm, friendly, compassionate relationships with others.

- The need for power, defined as the need to control or influence others'.

He observed that diverse persons have dissimilar stages of these needs. A number of them 'have a greater need for achievement, others a stronger need for affiliation, and still others a stronger need for power. Whereas one need may be central, though, this does not mean that the others are nonexistent'. According to McClelland, these three needs might be given 'different priorities at different levels of management'. Moreover, Achievement needs are mainly vital for achievement 'in many junior and middle management jobs where it is possible to feel directly responsibility for task accomplishment'. However 'in senior management positions a concern for institutionalized as opposed to personal power becomes more important'. Therefore, a strong need for attachment is not so important at any level.

\subsection{Herzberg's Two-Factor Theory Or Motivation-Hygiene Theory}

Herzberg et al. (1957) and Herzberg (1968) distinguished two types of motivational factors, "hygiene" factors and motivators. Which are also term as the two-factor model of satisfiers and dissatisfiers as well as intrinsic and extrinsic motivation. Any activities that are embark on for the direct satisfaction of one's needs are measured to be 'intrinsic motivation. Intrinsic motivation cause happy feelings or a good attitude within the worker and are task related. e. g. recognition of task completed'. The hygiene factors consist of wages, good working conditions, good company policy and administration, good relationships with supervisors and peers, and job security. The existence of these issues does not guarantee satisfaction and productivity. However if they are lacking, the employee will be disgruntled and discouraged. 'Satisfaction and productivity are only possible when the employee is positively motivated. Frederick Hertzberg's motivator-hygiene theory varies from Maslow's and Alderfer's needs hierarchy models as it does not propose that people change their needs 
over time. As an alternative Hertzberg put forward that employees are mostly motivated by growth and esteem needs, such as recognition, responsibility, advancement, achievement and personal growth (Rusua \& Avasilcaia 2014, Robins \& Coulter, 2012, Armstrong 2009, Mead \& Andrews 2009 McShane 2000 and Egbu n.d). In addition, Mead \& Andrews (2009) further stated that Herzberg applied his motivator-hygiene theory in the following techniques:

Job rotation - This involves planning the employee's time so that he performs a variety of tasks. For instance, he spends a period of time working in Process A, then moves to Process B, then moves to Process C. Job rotation introduces variety to the employee's routine, and helps develop a multi-skilled workforce. Employees may also be rotated to perform the same task in different settings. Japanese primary school teachers can expect to be rotated between schools every three years until, in their fifties, they are sent to the district office.

Job enlargement - involves reorganizing the job specification so that the employee now performs all the tasks required to complete the process. Rather than have Tasks $\mathrm{C}, \mathrm{D}, \mathrm{E}$ performed by employees $\mathrm{P}, \mathrm{Q}, \mathrm{R}$, respectively, all three tasks are allotted to each of $\mathrm{P}, \mathrm{Q}, \mathrm{R}$. In theory, the individual derives greater satisfaction from completing all tasks contributing to production and seeing the completed unit than from specializing in a single task.

Job enrichment- means making a job more interesting and more challenging, which in practice usually means more complex. First, responsibilities are pulled down from above, and the employee is trained to take new responsibilities for aspects of the task that previously were performed by a supervisor. Second, earlier work stages are pushed forward into the job. Third, later work stages are pulled back so that the employee is made responsible for up-stream and down-stream activities that were previously handled by other persons. Fourth, parts of the task are pushed down to a lower job level and are performed by lower grades (whose jobs are thus enriched by these responsibilities being pulled down). Fifth, parts of the job are rearranged and reordered.

\subsection{Intrinsic And Extrinsic Needs}

Many scholars have asserted that an individual is motivated to do what they do by both extrinsic and intrinsic factors. This explains that 'an individual can be motivated or driven by forces within an individual or forces outside an individual'. Motivation can be produced from inside the individual. This can be identified as intrinsic motivation (Gerson 2006). For instance, if a person has a sturdy aspiration to reach some goals or do something in order to achieve such aspiration or goals, therefore the individual has to act in a precise manner that will help him/her 'reach such desired goals'. Thus, 'intrinsic motivation is a form of self - actualisation in which a person needs to accomplish something worthwhile. In other words, it is self - generated or self- motivated and is free from financial rewards' (du Plessis et al 2016)

Motivation can also develop from outside the person and affects his/her behaviour and engagements which is well-known as extrinsic motivation. When mentioning the idea of extrinsic motivators to a work setting, it is undoubtedly understood that this kind of issue can influence most employees that come to work, as their work is consider as their main source of income (Neely, 2007, du Plessis et al 2016). The organization ought to attempt to make a link between intrinsic and extrinsic motivation. This is because if the employee are not provided with rewards and standard employment benefit packages they cannot be motivated and as a result will not devote their best effort that might produce good performance in the long run.

Needs are regularly defined in terms of a hierarchy. The most powerful hierarchy created is still the one that was designed by Maslow in 1954. It continues to impact 'theories of 
motivation and the design of incentive systems'. It displays how behavior is motivated at certain points by chances to satisfy intrinsic needs and at other points by another chances to satisfy extrinsic needs (Mead \& Andrews 2009).

\subsection{Expectancy Theory}

Vroom V.H (1964, Stráníková 2008, William 2010 and Egbu n.d) formulated the Expectancy theory. The theory endeavor to study the process of motivation. In order to progress with the study, Vroom uses three variables: "Valence" "expectancy" and "instrumentality". Valence is the measure of an individual's desire for certain results and stands for value. It may be positive (desired outcome) or negative (unattractive outcome). Expectancy is the belief that the output will lead towards expected performance. Instrumentality is the credence that after meeting the anticipated performance, the desired reward will be received. According to Vroom's formula, if one of these three variables is zero, motivation is absent: Motivation $=f$ (Valence $x$ Expectancy $x$ Instrumentality).

As valency stands for value, instrumentality the belief that one action will lead to another, and expectancy is the likelihood that action or effort will lead to an outcome. As a result, the 'strength of expectations' may perhaps base on 'past experiences (reinforcement), but individuals are frequently presented with new situations - a change in job, payment system, or working conditions imposed by management. In these circumstances, motivation may be reduced. Motivation is only likely when a clearly perceived and usable relationship exists between performance and outcome, and the outcome is seen as a means of satisfying needs'. The key support of this theory is that it takes a complete view of the motivational process and point out that individuals will only act when they have a realistic expectancy that their behaviour will lead to the desired outcome. (Armstrong 2009, Egbu n.d)

Bose (2004) elaborated on Vroom's theory which, clarifies the relationship between employee and organizational goals and; at the same time recognizes the differences between work and motivation. Besides, this theory is consistent with the awareness that a manager's job is to design the supporting environment for performance to take place by taking into account the various situations. So Vroom's theory is to a certain extent consistent with 'management by objectives' model. Schwind et al (2005) narrated a true story that serves as a good example of how the expectancy theory can be operationalized through the concept of 'management by objectives':

$1 *$ A bank manager needs to hire a teller. She interviews many applicants and decides on one who has the necessary abilities, skills, and traits. She gives the teller a through briefing on what will be expected of him, and explains how his performance will be measured. The teller also receives a job description that explains all the tasks he is expected to fulfill, complete with performance standards, priorities, and accountabilities (role clarity)

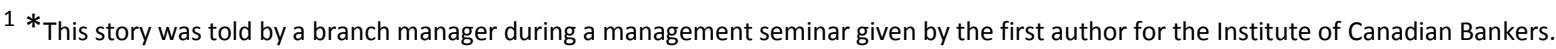
She had applied the expectancy model without knowing the theory in Hermann Schwind- Professor Emeritus, Saint Mary's University; Hari Das, Saint Mary's University and Terry wagar, Saint Mary's University.Canadian Human Resource Management. A strategic Approach $7^{\text {th }}$ edition, McGraw - Hill Ryerson 2005p422
} 
The manager makes sure that for the first few days the trainee is working with an experienced teller who guides him through the routines. The manager also does some roleplaying with the trainee to make sure that he knows how to react when he encounters any angry customer (thereby developing self-confidence). She also make it very clear to him that she is always available if he needs any help, and that he can also rely on the support of his colleagues in the branch (supervisory and peer support raises self-confidence)

The manager explains to the new teller how the bank's pay system works, and she describes the performance appraisal system and the criteria that are used to assess a teller's performance. She also discusses the performance objectives with the teller and agrees with him on some realistic goals and sets deadlines for their accomplishment. During the discussion, she tries to find out what rewards are valued by the teller. If, for example, it turns out that the teller is more interested in time off than in bonuses, the manager will keep this in mind for reward purposes.

The main element in expectancy model is the role clarity, which affects the degree to which employees apprehend their job, objectives, and their supervisor's expectations (Schwind et al 2005).

\subsection{Performance Management Practices}

Performance management (PM) practice is concern with the assessment and development of people at work. The practice has developed to be one of the most important features of today's operative organisations. In an ever more competitive work environment, organisations require to acquire the best out of their human resources if they are to subsist and flourish. If any organization fails to take that initiative, 'serious and sensitive questions about the general management competence' will be raised. Probably it will be attributed to a faulty operation of PM and appraisal type systems. However, the term ' performance management', like many HRM innovations, is a U.S. import that has been a major driver in the increased use of performance appraisal (PA) and management type practices across Europe [and subsequently in third world countries] ( McMahon G., 2013).

In addition, Performance management is a goal-oriented practice focused toward making sure that the organizational processes are in place to make best use of the productivity of employees, teams, and eventually, the organization. It is a major player in achieving organizational approach 'in that it involves measuring and improving the value of the workforce'. Moreover, PM take account of incentive goals and the matching incentive values so that the relationship can be clearly understood and communicated. There is a close connection between incentives and performance. Therefore, Performance management systems should be one of the most important focus in business today. Even though, every HR function contributes to performance management, training and performance appraisal also play a more important role. 'Whereas performance appraisal occurs at a specific time, performance management is a dynamic, ongoing, continuous process. Every person in the organization is a part of the PM system. Each part of the system, such as training, appraisal, and rewards, is integrated and linked for the purpose of continuous organizational effectiveness. With PM, the effort of each and every worker should be directed toward achieving strategic goals. If a worker's skills need to be improved, training is needed. With PM systems, training has a direct tie-in to achieving organizational effectiveness. In addition, pay and performance are directly related to achieving organizational goals (Chp8 PM \& P n.d). 
It is important to ask the question, why organisations like to review employees' performance? Better workplaces (n.d:70) gave a number of important reasons:

- Staff will more clearly understand how their work aligns with the overall business goals - what part they play in achieving these goals, what they should be doing and how they should be doing it. Employees are generally more productive, more enthusiastic and more committed when they know how they contribute to the business.

- Under-performance and its reasons (either work-related or personal) can be identified early, discussed and resolved before bigger problems arise.

- Potential skills gaps and appropriate training and skill development can be identified.

- Employees' career pathways can be defined more easily.

- Succession planning opportunities can be identified.

- Employees' welcome constructive feedback - a pat on the back for a job well done can increase productivity and commitment.

- A structured, regular performance appraisal or review creates an opportunity for staff to raise issues and concerns, and express their opinions about their work.

- Managers can discuss with employees what it is that they enjoy about their work and what motivates them - for example, achievement, advancement, responsibility, new challenges, learning or financial rewards.

- Absenteeism is likely to be reduced as a performance review process establishes regular communication and feedback with staff.

Managing performance is a worthy approach that will enable you to check if employees have the right skills, attitude and knowledge that are needed to accomplish your business objectives.

Consequent upon the literature reviewed on employee motivation and performance, it is evident that all theories were established on some experimentations or observations, as a result they are just written ends about a tested situation. Though circumstances can be comparable, they will perhaps by no means be the same. For that reason, managers should first of all direct their thoughtfulness towards their employees. They should observe the employees, communicate with them, so that they will be able to put together a portrait about their expectations and behaviors. Until this is accomplished managers might always choose which theory to follow (Stráníková, 2008).

\section{Research Methodology}

The author deed an armchair research in organizing this paper. The armchair research method was carried out to review the obtainable literature of this work. The study is exclusively based on secondary data. Secondary data has been collected from several sources including relevant books, journals and websites.

\section{Discussion}

Since the emergence of globalization the need to motivate employees has become prominent in management agendas. Managers nowadays are face with the challenge of getting 'highly performing' employees in order to meet organizational goals. It is no doubt that organizations are motivating their employees to get them to do what they want them to do in 
order to gain competitive advantage over their competitors in the market. Studies have showed that highly motivated employees that are productive and creative/innovative can lead the organization to success through the achievement of its desired results. Therefore, organization continued success will be largely dependent on its 'motivated employees'. As motivation is the self-directed behavior of a person to do what will get him the desired result (felt need). Thus, a highly motivated individual can always work assiduously to meet his/her performance objectives set by the company. And can sometimes go the extra - mile to surpass his/her target. For that reason, HR managers should endeavors to provide the enabling environment that will allow employees to make use of their expertise. This practice might influence employees to performance well and thereby minimize cost and maximize profit. Since managing performance is a way of investigating what type of skills, attitude and knowledge that employee needs to achieve the company goals.

For a greater understanding of motivation and performance many theories have forwarded to explain the concept of motivation and performance management such as: Maslow's hierarchy of needs which, discovered five elementary level of human needs and placed them in a chain of command such as Physiological needs, Safety needs, Social needs, Esteem needs and Self-actualization needs. This theory explains how people are motivated from the lower needs to the upper needs. Therefore, a satisfaction of one need leads to the motive to satisfy another need and so on. This process Maslow term as the 'satisfaction progression processes'. However, Maslow theory was unable to foretell employee needs and did not focus his theory on monetary desire. Nevertheless, Alderfer's ERG theory, tries to address the problem of moving from one satisfier to another. For Alderfer when the upper need is not satisfied (although the individual may be frustrated which, Alderfer referred to as 'the frustration regression processes') the person can rescind to the lower need and continues to enjoy the previous motivation. That is why he grouped his human needs into three broad categories such as: existence, relatedness, and growth in order to cow the difficulties of Maslow needs hierarchy.

However, Herzberg's motivator hygiene theory is the opposite of Maslow and Alderfer theories that state that self-actualization or growth is the main basis of motivation in the job. For Herzberg it is not true because; satisfying one need does not mean that there is no dissatisfiers on that need. For instance, the improvement on the hygiene factors may reduce dissatisfaction but, not increase satisfaction. The two-factor model of satisfiers and dissatisfiers was established by Herzberg et al (1957). The model emanating from a study piloted to be acquainted with the bases of job satisfaction and dissatisfaction of accountants and engineers. It is expected that people can express satisfaction or dissatisfaction on a job depending on the conditions embedded in the job.

On Vroom's expectancy theory, he uses three variables: "Valence"," expectancy" and "instrumentality". Valence quantify the person's needs based on the result produce. The outcome may be positive (anticipated outcome) or negative (unpleasant outcome). Expectancy is the conviction that the productivity of the worker can lead to the direction of predictable performance whilst; instrumentality is the belief that after meeting your target you then get the expected reward. Moreover, Vroom expectancy theory focuses mainly on the fulfillment of individual expectation in terms of performance delivery and the reward that follows. In addition, employee knows what the employer's expectations is in relation to the job and what his/her's own expectation is in terms of reward for a job well done. Therefore, this theory reward for hard work and accomplishment in order to increase motivation. Moreover, reward 
is linked with performance and the attractiveness of the reward can ignite the employee to go the extra- mile to deliver.

For intrinsic and extrinsic they explain how an individual can be motivated by forces within or forces outside. Thus, intrinsic factors consist of the want for accomplishment and the chance to do motivating work (self - actualization) whilst; extrinsic factors take account of 'needs for food, shelter and money'. However, this theory is to remind the managers that their job is to design the enabling environment that will promote/facilitate performance by taking into account different situations.

On the other hand, McClelland beliefs that learned needs can also be a source of motivation through the reinforcement of that behavior in dealing with teams or subordinates in accomplishing a task. McClelland's theory of learned needs studied three secondary needs that can motivate people such as: need for achievement, need for affiliation and need for power. He observed that different people have unrelated phases of needs. Some people 'have a greater need for achievement, while others a stronger need for affiliation, and others a stronger need for power'. According to McClelland, these three needs might be given 'different priorities at different levels of management'. He further pointed out that 'achievement needs' are mainly applicable 'in many junior and middle management jobs, where direct responsibility is being noticed for job achievement as oppose to senior management positions.

McGregor's theories $x$ and $y$ discovered two strikingly opposite sets of anticipations held by managers about their employees - in theory x managers assumed that the ordinary workers have little willpower, dislikes work and desires to avoid responsibility and cannot be trusted whilst, theory y emphasizes that people have self-direction in meeting objectives that they are committed to. Because of these perceptions, managers set targets for employees and use performance management practices to keep them committed on the job. Thus, the emergence of theory $\mathrm{Z}$ (i.e. a combination of theories $\mathrm{X}$ and $\mathrm{Y}$ ) by Ouchi was necessary in the management of the opposite sets of employees.

\section{Conclusion}

Thus, it is necessary to note that employees are the reason for the successful performance of organizations nowadays. It is evident that all theories were developed on some investigations or observations, as a result they are just written ends about a tested situation. Though circumstances can be comparable, they will perhaps by no means be the same. Also, studies have showed that highly motivated employees that are productive and creative can lead the organization to success through the achievement of its desired results. Therefore, managers should improve on their motivational strategies for the continued success of those organisations.

\section{References}

Armstrong Michael (2009), A Handbook of Human Resource Management Practice $11^{\text {th }}$ Edition Kogan Page London and Philadelphia

Bateman T. S. and Snell S. A. (2013) MANAGEMENT: Leading \& Collaborating in a Competitive World Tenth edition. Published by McGraw-Hill/Irwin

Better Workplaces (n.d) Employer Resource Kit Motivate Manage and Reward Performance. 67. 1 business.tas.gov.au pp67/70.

Bose, Chandra.D (2004) Principles of Management and Administration. Prentice Hall of India Limited. 
Burton Kelli (2012), A Study of Motivation: How to get your employees moving SPEA Honors Thesis Spring Indiana University

Chapter 8 (n.d) Performance Management and Appraisal - Semantic Scholar p326

du Plessis Andries J. and Dodd, Patrick (2016) HRM in Relation To Employee Motivation and Job Performance in the Hospitality Industry - Journal of International Business Research and Marketing Volume 1, Issue 4, May, 2016 pp13/14.

Egbu A Olomolaiye, C (n.d) Motivating Knowledge Workers: The Dilemma of HRM's contribution to Knowledge Management in the Construction Industry

Elena Nicu Ioana (n.d) Human Resources Motivation - An Important Factor in the development of Business Performance pp1039, 040.

Gerson, R. F. (2006). Achieving high performance: A research-based practical approach. Amherst, MA: HRD Press, Inc.

Herzberg, F W, Mausner, B and Snyderman, B (1957) The Motivation to Work, Wiley, New York

Herzberg, F (1968) One more time: how do you motivate employees?, Harvard Business Review, January February, pp 109-20

Luthans Fred and Doh Jonathan P. (2009), International Management: Culture strategy and behavior; Seventh edition, published by McGraw - Hill/Irwin.

Mead Richard and Andrews Tim G (2009) I n t e r $\mathrm{n}$ a $\mathrm{t}$ i o $\mathrm{n}$ a 1 Management CULTURE AND BEYOND F O U R T H E D I T I O N John Wiley and Sons, Ltd., Publication

McClelland, D C (1973) Testing for competence rather than intelligence, American Psychologist, 28 (1), pp 1-14

McGregor, D (1960) The Human Side of Enterprise, McGraw-Hill, New York

Maslow, A. (1954) Motivation and Personality, Harper \& Row, New York

McMahon Gerard (2013), Performance Management: Chapter 7 in Human Resource Management Dublin Institute of Technology ARROW@DIT.

McShane Steven L, (2000), and Von Glinow Mary Ann, Organisational Behavior. The McGraw - Hill Companies Inc.

Neely, A. (2007). Business performance measurement: Unifying theory and integrating practice (2nd ed.). London, UK: Cambridge University Press,

Robins Stephen P. and Coulter Mary(2012) Management eleventh edition Pearson Education, Inc., publishing as Prentice Hall, One Lake Street, Upper Saddle River, New Jersey 07458

Rusua Gabriela and Avasilcaia Silvia (2014) Linking human resources motivation to organizational climate 2014 The Authors. Published by Elsevier Ltd. Selection and peer-review under responsibility of SIM 2013/12th International Symposium in Management

Schwind H, Das H., and wagar T (2005.), Canadian Human Resource Management. A strategic Approach $7^{\text {th }}$ edition, McGraw - Hill Ryerson

Spacey John, (2017) 24 Types of Work Performance. Retrieved from https://simplicable.com/new/work-performance

Stráníková Daniela (2008) The Role of Motivation in Human Resource Management Bachelor paper Retrieved from https://dk.upce.cz/.../StranikovaD_The\%20role\%20of\%20motivation_IR_2008.pdf?.

Vroom, V (1964) Work and Motivation, Wiley, New York

William A. N. (2010) Employee Motivation and Performance Ultimate Companion Limited Douala-Cameroon Bachelor's Thesis Business Management December 2010 